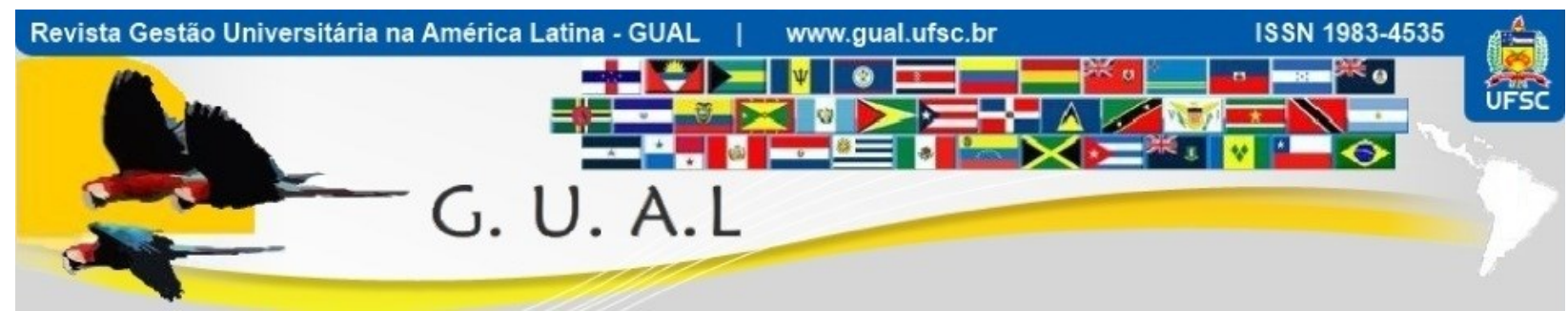

DOI: https://doi.org/10.5007/1983-4535.2021.72618

\title{
COMO DESCREVER UM PROFESSOR EXEMPLAR? PERCEPÇÕES DE ESTUDANTES DE GRADUAÇÃO EM ADMINISTRAÇÃO E CIÊNCIAS CONTÁBEIS
}

\section{HOW TO DESCRIBE AN EXEMPLARY TEACHER? PERCEPTIONS AMONG UNDERGRADUATE STUDENTS FROM MANAGEMENT AND ACCOUNTING COURSES}

Graziela dos Santos Bento, Mestre http://orcid.org/0000-0002-1488-2126 gsbento80@gmail.com Universidade Regional de Blumenau | Programa de Pós-Graduação em Ciências Contábeis e Administração Blumenau | Santa Catarina | Brasil

Larissa Kvitko, Mestre http://orcid.org/0000-0002-8911-3882 kvitko.la@hotmail.com

Universidade Federal Rural da Amazônia - Campus de Parauapebas | Curso de Administração Universidade Regional de Blumenau | Programa de Pós-Graduação em Ciências Contábeis e Administração

Blumenau | Santa Catarina | Brasil

Luciano Castro de Carvalho, Doutor https://orcid.org/0000-0002-1740-6053 luccar@gmail.com

Universidade Regional de Blumenau | Programa de Pós-Graduação em Ciências Contábeis e Administração Blumenau | Santa Catarina | Brasil

Recebido em 31/março/2020

Aprovado em 27/outubro/2020

Publicado em 01/janeiro/2021

Sistema de Avaliação: Double Blind Review

Apoio: Fundação de Amparo à Pesquisa e Inovação do Estado de Santa Catarina Brasil (FAPESC) - Chamada pública 03/2017. 


\title{
COMO DESCREVER UM PROFESSOR EXEMPLAR? PERCEPÇÕES DE ESTUDANTES DE \\ GRADUAÇÃO EM ADMINISTRAÇÃO E CIÊNCIAS CONTÁBEIS \\ DOI: https://doi.org/10.5007/1983-4535.2021.e72618
}

\begin{abstract}
RESUMO
Segundo Lowman (2005) a qualidade do ensino se relaciona com a habilidade do professor em criar estímulo intelectual e empatia interpessoal com os estudantes. O objetivo deste estudo é identificar como os estudantes de graduação em Administração (ADM) e Ciências Contábeis (CC) descrevem um professor exemplar, verificando se há diferença nas suas percepções, de acordo com o modelo de Lowman. O estudo foi realizado em uma universidade catarinense e consistiu em quatro grupos focais, de acordo com o curso e o semestre dos estudantes. Para análise foi utilizada a técnica de análise de conteúdo. A didática foi considerada a melhor característica de um professor exemplar. Enquanto os estudantes de ADM consideraram a necessidade de mais estímulos intelectuais, os de $\mathrm{CC}$ enfatizaram as relações interpessoais. A principal contribuição deste estudo está na comparação entre as percepções do que é um professor exemplar por estudantes de dois cursos complementares, porém com perfis de estudantes distintos. Além de confirmar os resultados obtidos em pesquisas anteriores, trouxe a importância dada pelos estudantes de ADM às atividades que aliam teoria e prática como um novo achado. Ainda, apresentou situações que ocorrem em sala de aula que podem gerar reflexões para melhorar a qualidade do ensino.
\end{abstract}

Palavras-chave: Qualidade do Ensino. Professor Exemplar. Administração. Ciências Contábeis. Modelo de Lowman.

\begin{abstract}
According to Lowman (2005), the quality of teaching is related to the teacher's ability to create intellectual stimulation and interpersonal empathy with students. The purpose of this study is to identify how undergraduate students from Management and Accounting courses describe an exemplary teacher. We also want to check if there is a difference in the perceptions of these students based on Lowman's model. The study was carried out at a university from Santa Catarina and consisted of four focus groups of students according to their course and semester. Data was analyzed using content analysis. Didactic was considered the best characteristic of an exemplary teacher. While Management students considered the need for more intellectual stimulation, Accounting students emphasized interpersonal relationships. The main contribution of this study is in the comparison between the perceptions of what an exemplary teacher is by students from two complementary courses, but with different student profiles. In addition to confirming the results obtained in previous research, it brought the importance given by Management students to activities that combine theory and practice as a new finding. Moreover, it presented situations that occur in the classroom that can generate reflections to improve the quality of teaching.
\end{abstract}

Keywords: Teaching Quality. Exemplary Teacher. Management. Accounting. Lowman's Model. 


\section{COMO DESCREVER UM PROFESSOR EXEMPLAR? PERCEPÇÕES DE ESTUDANTES DE \\ GRADUAÇÃO EM ADMINISTRAÇÃO E CIÊNCIAS CONTÁBEIS \\ DOI: https://doi.org/10.5007/1983-4535.2021.e72618}

\section{INTRODUÇÃO}

Em cursos de graduação em Administração frequentemente defende-se a realização de atividades ou trabalhos em grupo que reflitam a realidade do trabalho nas organizações, colocam o estudante em uma situação mais ativa, exercitam a colaboração e a comunicação entre grupos, entre outros aspectos (TESTA; FRONZA; FREITAS, 2005). Assim, os estudantes de Administração se destacam por constituírem um grupo que busca contato social para obter atenção, visando uma imagem positiva em um grupo ou na sociedade, uma vez que o curso valoriza mais o espírito de competição individual, enfatizando fortemente valores ligados à importância de líderes e do destaque no ambiente de trabalho, e outro que coloca em evidência os valores de interesse coletivo. (TESTA; ROHDE; LUCIANO, 2011).

A Contabilidade e a Administração caminham lado a lado, pois a Contabilidade se alimenta de informações, e estas são necessárias tanto para o planejamento como para as tomadas de decisão, sendo úteis no processo decisório, fornecendo conceitos e ferramentas básicas que propiciam ao Administrador desenvolver a capacidade de análise de relatórios com resultados operacionais da empresa (ALVES; TEIXEIRA; OLIVEIRA, 2017).

No entanto, a maioria dos estudantes de Ciências Contábeis, tanto de IES privadas como públicas, considera que a opção pelo curso de ciências contábeis tem relação com a habilidade com matemática e números. Embora a habilidade com matemática e números seja importante para a profissão, a contabilidade caracteriza-se como uma ciência social e não exata. Porém, a associação da contabilidade ao ramo das ciências exatas, especialmente no momento da escolha do vestibular, exerce forte influência na opção dos futuros contadores (SCHMIDT ET AL., 2012), dessa forma os caracterizando de forma diferente aos futuros administradores.

Essas reflexões levam à seguinte pergunta de pesquisa: dadas certas diferenças de perfil dos estudantes de administração e ciências contábeis, a percepção dos estudantes em relação ao conceito de um professor exemplar tende a ser diferente? O ensino exemplar é caracterizado por Lowman (2004, p. 41) como a "estimulação de emoções associadas à atividade intelectual: o estímulo para refletir sobre ideias, entender conceitos abstratos e enxergar a sua relevância na sua própria vida, e participar do processo da descoberta". Para Lowman (2004), o ensino universitário exemplar deve produzir um aprendizado ativo não somente dos fatos básicos, teorias e métodos, mas também das relações entre os diferentes ramos do conhecimento. Deve promover também o pensamento, as habilidades de 


\section{COMO DESCREVER UM PROFESSOR EXEMPLAR? PERCEPÇÕES DE ESTUDANTES DE \\ GRADUAÇÃO EM ADMINISTRAÇÃO E CIÊNCIAS CONTÁBEIS \\ DOI: https://doi.org/10.5007/1983-4535.2021.e72618}

comunicação e de resolução de problemas (AMARAL; DE RESENDE FREITAS; PINHEIRO, 2018).

O objetivo deste estudo é identificar como os estudantes dos cursos de graduação em Administração e Ciências Contábeis descrevem um bom professor, verificando se há diferença nas percepções destes alunos por curso. Estudos recentes analisaram o perfil de um professor exemplar nos cursos de administração e ciências contábeis na graduação (ANTONELLI ET AL., 2018; BENI, 2017; KVITKO; LENGLER, 2015), pós-graduação lato sensu (NOGUEIRA; FADEL; TAKAMATSU, 2012), pós-graduação stricto sensu (AMARAL; DE RESENDE FREITAS; PINHEIRO, 2018), porém a maioria dos estudos abordou a pesquisa de forma quantitativa.

Assim, busca-se contribuir para a análise do perfil de um professor exemplar dando voz aos estudantes para que eles possam conceituar, com base em suas percepções, um bom professor, baseados nas dimensões de Lowman. O método de pesquisa utilizado será o de grupo focal e os procedimentos seguiram aqueles aplicados por Kvitko e Lengler (2015).

\section{REVISÃO DE LITERATURA}

Lowman (2004), inspirado pelas próprias observações de um grupo de 25 professores exemplares em Instituições de Ensino Superior americanas, desenvolveu um modelo bidimensional de efetividade do ensino universitário. Segundo o autor, a qualidade do ensino está relacionada com a habilidade do professor em criar estímulo intelectual e empatia interpessoal com os estudantes - "espécies de emoção e relacionamento que os motivam a dar o melhor de si no trabalho". As habilidades em gerar estímulo e em estabelecer relacionamento são relativamente independentes, segundo o autor.

Antonelli et al. (2018) explicam que o modelo de Lowman apresenta, na Dimensão I, dois componentes: (i) clareza na apresentação do professor que é relacionada com o que se apresenta; e (ii) impacto emocional estimulante sobre os alunos, relacionado com o modo que o material é apresentado. Logo, parte-se do pressuposto que o professor conhece o conteúdo que está lecionando. Portanto, o professor que consegue dominar o conteúdo e transmiti-lo com clareza terá grandes possibilidades de atingir o objetivo de transmitir o conhecimento. Por outro lado, a Dimensão II trata da consciência que o professor tem dos fenômenos interpessoais e de sua habilidade em se comunicar com os estudantes, de modo a aumentar a motivação, o prazer e o aprendizado autônomo. 


\section{COMO DESCREVER UM PROFESSOR EXEMPLAR? PERCEPÇÕES DE ESTUDANTES DE \\ GRADUAÇÃO EM ADMINISTRAÇÃO E CIÊNCIAS CONTÁBEIS \\ DOI: https://doi.org/10.5007/1983-4535.2021.e72618}

Investigações ao longo do tempo contribuíram com a identificação de características primordiais ao bom professor, como conhecimento e didática, usando o modelo de Lowman como referência. Lumpkin e Multon (2013) pesquisaram um grupo de professores reconhecidos como "excepcionais" em uma grande universidade de pesquisa para explorar o que eles consideram ser um professor exemplar. O método de pesquisa utilizado foi a survey, por meio de um instrumento que englobava as principais dimensões identificadas na revisão de literatura, entre elas as de Lowman, para avaliar as características de um bom professor. Os professores afirmaram que gostavam de ensinar e expressaram uma forte preferência por envolver ativamente os alunos no processo de aprendizagem e atribuir um alto grau de importância ao recebimento de feedback dos alunos. Eles enfatizaram a importância de estabelecer expectativas e objetivos claros, fornecer feedback oportuno e usar uma variedade de abordagens de apresentação e instrução e enfatizaram que seu ensino e pesquisa eram interconectados e sinérgicos.

Kvitko e Lengler (2015) usaram o modelo de Lowman para estudar as características consideradas relevantes na avaliação dos professores por estudantes de graduação do curso de Administração. Para isso, foram realizados quatro grupos de foco, cujos resultados mostraram uma concordância dos alunos em relação às dimensões de estímulo intelectual e empatia interpessoal.

Nogueira, Fadel e Takamatsu (2012), avaliaram as características determinantes de um bom professor, por meio da aplicação de questionários aos alunos do curso de pós-graduação (lato sensu) na área de negócios de uma universidade paranaense. Os resultados do estudo demonstraram que as características relacionadas ao Conhecimento e Didática e aos atributos Pessoais/Comportamentais foram predominantes na determinação de um bom professor. Além disso, apesar de estatisticamente inferiores, os resultados demonstram que os alunos atribuem importância a características físicas e relacionadas a Tecnologia.

Amaral, De Resende Freitas e Pinheiro (2018) identificaram quais as características que os alunos dos cursos de mestrado e doutorado, na área de Ciências Contábeis, consideram pertinentes ao professor exemplar, por meio de questionário eletrônico, elaborado a partir de estudos que utilizaram como base o modelo de Lowman. Os resultados da pesquisa indicam que o perfil de um professor exemplar pode ser definido como aquele profissional docente que exibe características ligadas ao relacionamento com os alunos e, ainda, ao planejamento, conhecimento e didática. 


\section{COMO DESCREVER UM PROFESSOR EXEMPLAR? PERCEPÇÕES DE ESTUDANTES DE \\ GRADUAÇÃO EM ADMINISTRAÇÃO E CIÊNCIAS CONTÁBEIS \\ DOI: https://doi.org/10.5007/1983-4535.2021.e72618}

Antonelli et al., (2018) destacaram as características de um bom professor na visão dos discentes de Ciências Contábeis da Geração Y, por meio de questionário aplicado em duas Instituições de Ensino Superior privadas e uma pública. Os principais achados indicam que os discentes consideram em ordem de importância as seguintes características de seus docentes: conhecimento e domínio de conteúdo; clareza nas explicações, didática e preparo de conteúdo; relacionamento entre os acadêmicos e os docentes e a tecnologia em meio ao ensino superior; e atributos pessoais dos docentes. Com relação às instituições de ensino, observaram-se diferenças nas percepções dos discentes da pública com relação às privadas pesquisadas.

Beni (2017) buscou entender como acontece o processo de ensino-aprendizagem e a interação de professores e alunos em cursos de graduação em Administração de Empresas por meio de uma pesquisa qualitativa em uma universidade particular da cidade de São Paulo. Os resultados demonstraram que, mesmo seguindo o conteúdo programático e atendendo às exigências da instituição e do Projeto Político-Pedagógico, os professores, em geral, possuem um bom relacionamento com as turmas e mostraram-se flexíveis com as demandas dos alunos. Em todas as observações, pôde-se verificar que os docentes tentaram promover um ambiente dinâmico e incentivador ao aluno.

Busler et al. (2017) investigou as percepções dos alunos sobre o mau ensino universitário. Estudantes geraram uma lista dos 5 principais comportamentos que seus professores mais ineficazes exibiram: ser desrespeitoso, oferecer avaliações de aprendizagem não representativas e injustas, ter expectativas irreais para a aprendizagem do aluno, ter pouco conhecimento sobre o conteúdo do curso e habilidades de comunicação precárias.

De maneira geral, todas essas pesquisas confirmam a predominância de características relacionadas as duas dimensões do Modelo de Lowman.

\section{METODOLOGIA}

A pesquisa foi caracterizada como descritiva de abordagem qualitativa, com uso de dados primários provindos de quatro grupos focais com seis estudantes cada, compostos por: um grupo do segundo período e um grupo do oitavo período de ADM; um grupo do segundo período e outro do oitavo período de CC. A coleta de dados ocorreu na Universidade Federal de Santa Catarina, em abril de 2019. 


\section{COMO DESCREVER UM PROFESSOR EXEMPLAR? PERCEPÇÕES DE ESTUDANTES DE \\ GRADUAÇÃO EM ADMINISTRAÇÃO E CIÊNCIAS CONTÁBEIS \\ DOI: https://doi.org/10.5007/1983-4535.2021.e72618}

A adoção da técnica de grupos focais para a coleta de dados permite a interação grupal para a discussão participativa de uma temática, além de proporcionar uma relação de confiança entre os participantes (KINALSKI ET AL, 2017). Este tipo de abordagem ressalta a necessidade de considerar a visão de diferentes sujeitos e contextos sociais sobre os quais incidem o fenômeno a ser avaliado (TANAKA; MELO, 2004). O roteiro utilizado foi constituído por seis perguntas abertas:

- O que é ser um bom professor?

- Que tipo de atitudes os professores possuem que te deixam feliz ou triste?

- Qual a diferença entre um professor querido e um bom professor? E entre um professor eficiente e um bom professor?

- Quais as características de um bom professor? Quais as ações que os professores mais eficientes tomam?

- Pense num professor ídolo que você tem. Quais as características que ele possui para considerá-lo ídolo?

- O que um bom professor jamais pode fazer em sala de aula?

Num primeiro momento, a moderadora conversou com os coordenadores dos dois cursos, apresentando a pesquisa e solicitando permissão para visitar as salas de aula e convidar estudantes a participarem. Conforme o planejamento, foram escolhidas duas turmas de fases iniciais e duas turmas de fases finais de cada curso, para que fosse possível fazer uma comparação entre ambas, a fim de conhecer se existem diferenças de opinião entre elas, com relação às características dos professores. Na sequência, a moderadora visitou as salas de aula do segundo e oitavo semestre de ambos os cursos, convidando os estudantes a participarem da pesquisa. Assim, os alunos participantes foram todos aqueles que voluntariamente expressaram o desejo de contribuir com a pesquisa.

As entrevistas de cada grupo foram filmadas individualmente, e transcritas em formato de texto. O método utilizado para a análise de dados foi a análise de conteúdo (BARDIN, 2011). A análise de conteúdo é "uma técnica de investigação que através de uma descrição objetiva, sistemática e quantitativa do conteúdo manifesto das comunicações tem por finalidade a interpretação destas mesmas comunicações".

As transcrições das entrevistas foram então inseridas no software para análise de dados qualitativos Atlas TI v. 7.5. Após esta etapa, as transcrições foram lidas duas vezes cada, e destacadas as sentenças que citavam características que poderiam ser enquadradas nas duas dimensões de Lowman: estímulo intelectual e empatia interpessoal com os estudantes. Essas 


\section{COMO DESCREVER UM PROFESSOR EXEMPLAR? PERCEPÇÕES DE ESTUDANTES DE \\ GRADUAÇÃO EM ADMINISTRAÇÃO E CIÊNCIAS CONTÁBEIS \\ DOI: https://doi.org/10.5007/1983-4535.2021.e72618}

sentenças foram então classificadas em categorias criadas a partir da interpretação e consenso dos pesquisadores. Ao final da categorização dos dados de todos os 4 grupos focais, os dados foram contabilizados para responder à pergunta de pesquisa: dadas certas diferenças de perfil dos estudantes de administração e ciências contábeis, a percepção dos estudantes em relação ao conceito de um professor exemplar tende a ser diferente?

\section{ANÁLISE DOS RESULTADOS}

Os grupos focais permitiram que os estudantes se expressassem abertamente, com suas próprias palavras, sobre as características de um professor exemplar. $\mathrm{O}$ debate gerou uma fonte rica de dados, ao deixar os participantes determinarem quais características são mais relevantes para eles, e complementarem suas ideias, concordâncias e discordâncias com exemplos ilustrativos. O quadro 1 apresenta a síntese das categorias que emergiram da análise de conteúdo das transcrições.

Quadro 1 Categorias que emergiram dos grupos focais

\begin{tabular}{|c|c|c|}
\hline $\begin{array}{c}\text { Dimensão } \\
\text { Lowman }\end{array}$ & Categoria & Conceito \\
\hline \multirow{16}{*}{ 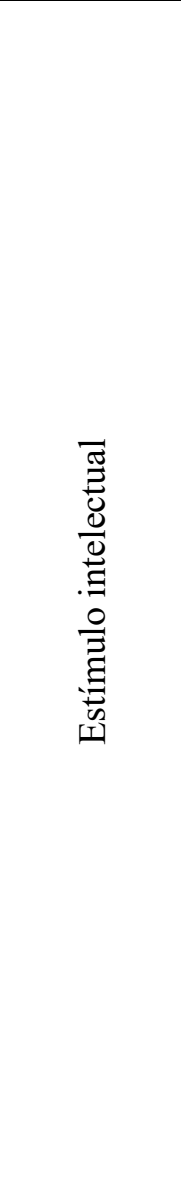 } & Atividades extra-classe & Disponibiliza materiais e atividades extra-classe \\
\hline & Atualização & $\begin{array}{l}\text { Apresenta material atualizado, com exemplos } \\
\text { recentes }\end{array}$ \\
\hline & Conhecimento & $\begin{array}{l}\text { Demonstra conhecimento da disciplina que } \\
\text { leciona }\end{array}$ \\
\hline & Desperta interesse & Desperta o interesse dos alunos para o conteúdo \\
\hline & Didática & $\begin{array}{l}\text { Transmite o conhecimento de uma forma clara e } \\
\text { eficiente }\end{array}$ \\
\hline & Dúvidas & Tira dúvidas \\
\hline & Exigência & É exigente \\
\hline & Gosta do que faz & Gosta do que faz, ensina com entusiasmo \\
\hline & Inovação & $\begin{array}{l}\text { É inovador, utiliza várias metodologias de ensino } \\
\text { e incentiva a criatividade }\end{array}$ \\
\hline & Interação & Promove interação \\
\hline & Motivação & $\begin{array}{l}\text { Motiva os alunos a buscarem mais, como } \\
\text { estudantes e profissionais }\end{array}$ \\
\hline & Planejamento/organização & $\begin{array}{l}\text { Planeja e organiza bem a aula: conteúdos, tempo, } \\
\text { recursos didáticos, procedimentos metodológicos, } \\
\text { instrumentos e critérios de avaliação }\end{array}$ \\
\hline & Preocupação com o público-alvo & $\begin{array}{l}\text { Adequa o conteúdo e a linguagem de acordo com } \\
\text { o público-alvo }\end{array}$ \\
\hline & Teoria/prática & Relaciona a teoria às práticas do dia-a-dia \\
\hline & Tom de voz & $\begin{array}{l}\text { Tem um tom de voz claro e audível, língua } \\
\text { entendível }\end{array}$ \\
\hline & Visão sistêmica & Tem uma visão sistêmica e interdisciplinar \\
\hline
\end{tabular}




\section{COMO DESCREVER UM PROFESSOR EXEMPLAR? PERCEPÇÕES DE ESTUDANTES DE \\ GRADUAÇÃO EM ADMINISTRAÇÃO E CIÊNCIAS CONTÁBEIS \\ DOI: https://doi.org/10.5007/1983-4535.2021.e72618}

\begin{tabular}{|c|c|c|}
\hline $\begin{array}{c}\text { Dimensão } \\
\text { Lowman }\end{array}$ & Categoria & Conceito \\
\hline \multirow{8}{*}{ 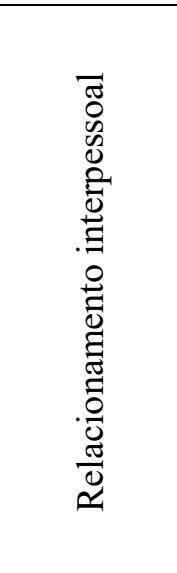 } & Bom humor & Tem bom humor \\
\hline & Debate/pensamento crítico & Incentiva o debate e o pensamento crítico \\
\hline & Disponibilidade & Tem disponibilidade para atender alunos \\
\hline & Empatia & É empático e humano \\
\hline & Feedback & $\begin{array}{l}\text { Dá feedback aos alunos sobre atividades e } \\
\text { avaliações }\end{array}$ \\
\hline & Flexibilidade/resiliência & $\begin{array}{l}\text { É capaz de mudar algo que não esteja } \\
\text { funcionando }\end{array}$ \\
\hline & Imparcialidade & $\begin{array}{l}\text { É imparcial, respeita as diferenças, evita assuntos } \\
\text { polêmicos }\end{array}$ \\
\hline & Preferências & $\begin{array}{l}\text { Pergunta sobre as preferências dos alunos em } \\
\text { algumas questões }\end{array}$ \\
\hline
\end{tabular}

Fonte: Dados da pesquisa

As categorias listadas e descritas no quadro 1 foram obtidas e refinadas no software Atlas TI, destacando-se as menções no texto e atrelando-as às classes genéricas, baseadas em Lowman (2005), e posteriormente ampliadas de acordo com o surgimento de novas características ou refinadas quando do surgimento de categorias semelhantes.

$\mathrm{Na}$ sequência, foi realizada a contagem das classes para as turmas do segundo período de ADM e CC, conforme Tabela 1.

Tabela 1 Comparativo entre $2^{\circ}$ período de Administração e Contábeis

\begin{tabular}{l|c|c|c}
\hline \multicolumn{1}{c|}{ CATEGORIA } & ADM & CC & TOTAL \\
\hline Didática & 11 & 11 & 22 \\
\hline Teoria/prática & 8 & 6 & 14 \\
\hline Debate/pensamento crítico & 6 & 0 & 6 \\
\hline Preocupação com o público-alvo & 6 & 3 & 9 \\
\hline Dúvidas & 5 & 8 & 13 \\
\hline Despertar o interesse & 5 & 4 & 9 \\
\hline Gostar do que faz & 5 & 0 & 5 \\
\hline Atividades extra-classe & 5 & 0 & 5 \\
\hline Empatia & 4 & 11 & 15 \\
\hline Interação & 4 & 4 & 8 \\
\hline Inovação & 4 & 3 & 7 \\
\hline Tom de voz & 4 & 0 & 4 \\
\hline Planejamento/organização & 1 & 7 & 8 \\
\hline Disponibilidade & 0 & 7 & 7 \\
\hline Imparcialidade & 2 & 5 & 7 \\
\hline Motivação & 0 & 4 & 4 \\
\hline Bom humor & 0 & 4 & 4 \\
\hline
\end{tabular}

Fonte: Dados da pesquisa 


\section{COMO DESCREVER UM PROFESSOR EXEMPLAR? PERCEPÇÕES DE ESTUDANTES DE \\ GRADUAÇÃO EM ADMINISTRAÇÃO E CIÊNCIAS CONTÁBEIS \\ DOI: https://doi.org/10.5007/1983-4535.2021.e72618}

A característica de um professor exemplar mais citada por estudantes do segundo período de ambos os cursos foi a didática, ou seja, a capacidade de transferir conhecimento de forma eficaz. Essa característica foi comentada várias vezes nos dois grupos:

[...] um professor que tenha disciplina, que ele não se perca enquanto ele explica e que ele siga uma linha de raciocínio do início até o fim [...].

[...] um professor disposto realmente a ensinar o aluno. Tem professor que realmente vem pra sala que não tá preparado que se perde no assunto e que não sabe criar uma linha de raciocínio que não sabe dar exemplo entendível pra gente, então, é um professor que vem mais pra cumprir hora do que pra cumprir currículo $[\ldots]$.

Tem muitos professores que são muitos prestativos em fazer a turma entender todo mundo junto e as pessoas que não estão entendendo fazer caminhar junto e saber prestar atenção nos pequenos pontos e fazer todo mundo caminhar em uma direção só [...].

O professor tem que ser inteligente, não no sentido saber tudo, mas inteligente na questão de organizar as ideias dele pra repassar pros alunos.

No caso da turma de CC, empatada com a didática, vem a característica de empatia, pouco citada pela turma de ADM, assim como identificado por Amaral, De Resende Freitas e Pinheiro (2018): características ligadas ao relacionamento com os alunos e, ainda, ao planejamento, conhecimento e didática. Neste caso, espera-se um professor que se coloque no lugar no aluno, seja humano, respeitando as diferenças.

[...] tem que entender as necessidades dos alunos.

[...] tinha um professor que já chegou dizendo que todo mundo rodava naquela matéria que era muito difícil e que era horrível e no final das provas, era prova final, ele disse que tinha certeza que quase ninguém ia passar, isso gera nos alunos muito medo e também ansiedade.

Acho que empatia é uma coisa muito importante porque a Professora XXXX fala bastante que ela achava que a prova não era um método eficaz de analisar um aluno e tal, porque realmente pode ser no dia que você não está legal. Dava trabalhinho e não sei o que, então acho que empatia é um ponto muito forte porque você tem que tá ali pelo aluno, você passou por isso, então sabe como é.

[...] quando o professor tem empatia por um aluno que não tá indo bem, tá precisando de uma nota, e sabe que o aluno tá se esforçando e consegue horários e foca nesse aluno, dá mais tempo e explica as coisas.

Para a turma de ADM, a segunda característica mais citada foi a capacidade de relacionar a teoria às práticas do dia-a-dia. Uma das explicações para este fato pode estar 
relacionada à necessidade de aplicar os conhecimentos numa situação real, e identificar casos de sucesso e insucesso para guiar as decisões destes estudantes quando estiverem nas organizações.

Ele trazia muita coisa do dia a dia assim, tipo ahhh, essa empresa fez esse pronunciamento, mas porque que ela fez esse pronunciamento? Vocês vão ter que desenvolver uma contraproposta pra esse pronunciamento.

Eu tive uma matéria do curso de empreendedorismo e inovação com o XXX. O cara é muito massa. Aí era uma aula tipo um workshop e, ele pegava uma empresa, ele dava todo o material, a gente era tipo um empreendedor, então a gente tinha que fazer todo o modelo, fazer tudo...ele meio que desconstruiu, ele não deu tipo: leiam isso! Essa matéria dele foi muito legal.

Já nessa perspectiva, os estudantes de CC preferem que os professores tirem as dúvidas. A falta dessa característica em professores foi uma das principais fontes de reclamação do grupo.

É uma professora que ela explica, o jeito dela explicar é completamente diferente dos outros professores porque ela lê o slide, mas assim, ela sempre tira dúvida, ela sempre vai tirando dúvida. Isso faz com que a aula dela seja eficiente e além disso ela coloca sempre uma lista de exercício no final da aula, e se restou ainda alguma dúvida, se vê naquela lista de exercícios.

Eu considero uma característica boa o professor que tenha disponibilidade de tirar dúvidas e disponibilidade de querer também, se fazer ser entendido, porque as vezes tem professor que acham que tirou tua dúvida falam qualquer coisa e na verdade tu não entendeu nada.

[...] mesmo que a pessoa tiver uma dúvida sobre o início da explicação dele ele volte e reexplique e que ele não fale que ele já explicou ou que vai deixar para depois porque essa dúvida poderia fazer o aluno entender melhor o que ele está explicando agora.

Já na comparação entre os estudantes do oitavo período dos dois cursos, houve uma diferença nos resultados. Os alunos de CC destacaram fortemente a didática como principal característica, enquanto para os estudantes de ADM os resultados ficaram mais distribuídos entre teoria/prática, Feedback e dúvidas, conforme pode ser visto na Tabela 2.

Tabela 2 Comparativo entre $8^{\circ}$ período de Administração e Contábeis

\begin{tabular}{l|c|c|c}
\hline CATEGORIA & ADM & CC & TOTAL \\
\hline Teoria/prática & 6 & 4 & 10 \\
\hline Feedback & 6 & 1 & 7 \\
\hline Dúvidas & 5 & 4 & 9 \\
\hline Didática & 4 & 17 & 21 \\
\hline Empatia & 4 & 5 & 9 \\
\hline Inovação & 4 & 4 & 8 \\
\hline
\end{tabular}

Fonte: Dados da pesquisa 
Quando perguntados, por exemplo, se há relação entre ser um professor querido e um bom professor, os estudantes de $\mathrm{CC}$ responderam que ter didática é mais importante do que ser um professor querido:

Eu acho que não tem relação necessariamente, porque tem muitos professores que apesar de serem queridos e se darem bem com os alunos, não tem o conhecimento e a didática suficiente para passar isso pros alunos.

[...] não precisa ser querido pra ser eficiente.

Novamente, no oitavo período de ADM, a relação entre a teoria e prática ficou entre as características mais citadas:

[...] o que me deixa feliz, eu particularmente eu adoro quando tem parte prática, quando um professor traz atividades pra gente praticar em sala de aula, em grupo, apresentações assim, eu gosto bastante dessas atividades, mas pela questão prática mesmo.

Trazer não só o slide, incluir exercícios, trazer exemplos da nossa vida diária pra sala de aula.

[...] o que me deixa feliz, é justamente essa questão de trazer a didática de uma forma diferente uma forma inovadora de conseguir juntar o que a gente aprende em teoria com que a gente aprende, que no caso, com a pratica, a gente está tento uma matéria agora que ela é completamente prática a gente tem que administrar toda uma empresa do zero. Então pra gente é, como engloba todas as disciplinas praticamente então a gente consegue ver como aquilo funciona. Não fica só no conteúdo e nem na imaginação, a gente coloca a mão na massa pra colocar em prática.

Além da relação entre teoria e prática, alguns estudantes de ADM ressaltaram ainda, a importância do feedback:

Ter uma forma diferente de se comunicar com gente pra gente, dar um feedback; não precisa ser sempre positivo, mas pelo menos que faça a gente refletir sobre aquilo e melhorar o que a gente fez.

[...] dar um feedback pra gente. Muitas vezes a gente faz trabalho que depois a gente nunca sabe o porquê daquilo, se a gente seguiu o caminho certo, se era isso mesmo.

Em resumo, respondendo à pergunta de pesquisa: "Dadas certas diferenças de perfil dos estudantes de administração e ciências contábeis, a percepção dos estudantes em relação ao conceito de um professor exemplar tende a ser diferente?", podemos responder que sim. Apesar de haver um consenso entre os estudantes do segundo período de que a didática é a 
característica mais importante de um professor exemplar, é possível ver uma distinção interessante entre os dois grupos no que diz respeito às demais características citadas.

Enquanto os estudantes de ADM priorizam características como capacidade de relacionar teoria e prática, incentivo ao debate e ao pensamento crítico e a adequação do conteúdo e linguagem ao público-alvo, os estudantes de CC consideram um professor exemplar aquele que se coloca no lugar dos alunos e tira dúvidas.

"Essa questão do debate, do aluno falar mais, de dar uma alfinetada nesse senso crítico, de saber pensar fora da caixinha e do que tá escrito ali no slide, acho que é o mais importante.

[...] hoje em dia a gente tem tanta informação, a informação que ele tá dando pode ser muito importante, mas eu posso achar isso no google. Eu acho que ele tem que estar mais junto. Eu acho que tem professor que desconstrói muito na sala de aula, bota todo mundo junto, incentiva o pensamento crítico que eu acho que é muito importante, acho que hoje em dia isso tá faltando $[\ldots]$.

[...] ir moldando todo conteúdo e estrutura da aula de acordo com a turma, ter essa malemolência pra perceber a rapidez ou a lentidão da turma e conseguir entender melhor o que não funciona com aquele grupo de pessoas.

[...] um professor que utiliza uma linguagem mais carismática, mais jovem, que os jovens tão acostumados.

Há diferença também entre os estudantes do oitavo período dos dois cursos. Os estudantes de CC relataram basicamente a didática como característica essencial de um professor exemplar, enquanto os estudantes de $\mathrm{ADM}$ citaram várias características consideradas importantes, como teoria/prática, feedback, dúvidas, didática, empatia e inovação.

Finalmente, respondendo à pergunta "O que um bom professor jamais pode fazer em sala de aula?", os estudantes apontaram alguns maus comportamentos que os deixam insatisfeitos, em linha com o pior mau comportamento identificado por Busler et al. (2017): ser desrespeitoso com o aluno.

[...] eu tive um professor que era muito bom, ele tinha uma didática ótima, a gente sabia que ele tinha conhecimento. Mas era muito arrogante e fazia com que eu não gostasse dele.

[...] um bom professor jamais pode debochar do aluno em sala de aula. 
Eu acho que esse negócio de ironizar as perguntas de aluno, achar que não é interessante, não sei, eu acho que isso é bem sério, acho que deixa o aluno mais intimidado com a matéria.

Ficar o tempo todo se autoafirmando: você está errado com essa opinião eu tenho mestrado, eu tenho doutorado, eu sou formado nisso, tive experiência naquela empresa $[\ldots]$.

Expor o aluno. Tinha um professor nosso que entregava a prova por ordem decrescente de nota e eu achava isso um pouco triste, porque ia chegando uma hora em que, por exemplo, você tirou 4 e depois de você ele entregava pra mais umas 15 pessoas e você sabia que aquelas pessoas tinham tirado nota pior que você.

Acredito que os professores que são preconceituosos em diversos âmbitos e que falam sua opinião na sala com se fosse uma coisa super natural.

Constranger o aluno. Eu acho que as vezes a pessoa não se sente à vontade pra falar, ou é mais tímida, enfim, eu acho que é deixar cada um à vontade pra falar, expor sua opinião, se quiser.

O professor não pode ser um cara muito dogmático. Tem que estar aberto as novas teorias, tem que entender que o conhecimento é renovado todo o tempo.

Assim, houve um consenso entre todos os dois cursos e períodos sobre a pior coisa que um professor pode fazer em sala de aula. Desrespeitar um aluno é algo considerado inaceitável em qualquer situação. Infelizmente, de acordo com os relatos, ainda é algo comum nas salas de aulas destes dois cursos. Essa característica está relacionada à dimensão de Relacionamento interpessoal de Lowman, no quesito empatia/humanidade.

Os resultados gerais da pesquisa confirmam os resultados de pesquisas anteriores. Estudantes de $\mathrm{CC}$ consideram como características mais importantes aquelas relacionadas à didática, em linha com os achados de Antonelli et al., (2018), que indicaram, em ordem de importância, as seguintes características de seus docentes: conhecimento e domínio de conteúdo; clareza nas explicações, didática e preparo de conteúdo; relacionamento entre os acadêmicos e os docentes e a tecnologia em meio ao ensino superior; e atributos pessoais dos docentes.

Em relação aos estudantes de ADM, destaca-se a importância do docente promover atividades que conciliem teoria e prática, uma vez que a Administração é uma ciência totalmente aplicada e cada organização possui características e culturas diferentes. 


\section{COMO DESCREVER UM PROFESSOR EXEMPLAR? PERCEPÇÕES DE ESTUDANTES DE \\ GRADUAÇÃO EM ADMINISTRAÇÃO E CIÊNCIAS CONTÁBEIS \\ DOI: https://doi.org/10.5007/1983-4535.2021.e72618}

Essa é outra contribuição da pesquisa, uma vez que não foram identificadas menções à importância dessa relação entre teoria e prática para estudantes de administração na revisão de literatura efetuada.

\section{CONSIDERAÇÕES FINAIS}

O objetivo deste estudo foi de identificar como os estudantes dos cursos de graduação em Administração e Ciências Contábeis descrevem um professor exemplar, verificando se há diferença nas percepções destes alunos por curso, baseado no modelo bidimensional de Lowman.

A partir da análise do conteúdo gerado nos grupos focais, foi possível identificar que existem diferenças entre a percepção dos estudantes dos cursos de Administração e Ciências Contábeis em relação às características de um professor exemplar. A capacidade de transmitir o conhecimento de forma clara (didática) é uma característica importante num professor exemplar para ambos os cursos. No entanto, enquanto os estudantes de administração priorizam características da dimensão relacionada ao estímulo intelectual, percebe-se uma maior necessidade de características da dimensão relacionada ao relacionamento interpessoal (empatia/humanidade) pelo grupo de Ciências Contábeis, principalmente nos períodos iniciais.

A principal contribuição deste estudo está na comparação entre as percepções de um professor exemplar por estudantes de cursos que são, ao mesmo tempo, complementares, porém com perfis de estudantes distintos. Ainda, confirmou resultados obtidos em pesquisas quantitativas, obtendo resultados similares para a maioria das características. No entanto, um resultado que chamou atenção foi o destaque da importância dada pelos estudantes de administração à necessidade de o docente aliar teoria e prática em suas aulas.

Finalmente, apresenta as percepções dos alunos, com exemplos positivos e negativos em sala de aula, que podem gerar reflexões para melhorar o desempenho de professores destes cursos, contribuindo com uma melhor formação e satisfação dos alunos de acordo com o modelo de Lowman (2004).

A realização deste estudo apresentou algumas limitações. Por exemplo, os grupos foram filmados para facilitar a transcrição posteriormente, o que pode gerar certa preocupação dos participantes em relação ao anonimato, apesar da garantia de confidencialidade informada pela moderadora. Além disso, num grupo focal, há o risco de que as discussões sejam 


\section{COMO DESCREVER UM PROFESSOR EXEMPLAR? PERCEPÇÕES DE ESTUDANTES DE \\ GRADUAÇÃO EM ADMINISTRAÇÃO E CIÊNCIAS CONTÁBEIS \\ DOI: https://doi.org/10.5007/1983-4535.2021.e72618}

dominadas por poucas pessoas, enviesando os resultados. Para prevenir o viés, cada participante foi estimulado a responder às perguntas do roteiro, e os resultados foram analisados dentro do contexto do grupo. Ainda, a composição intencional e de conveniência da amostra acaba por limitar as possibilidades de generalização para a população investigada (TRAD, 2009). Finalmente, é importante ressaltar que os grupos focais foram realizados com estudantes de uma instituição pública. O estudo de Antonelli et al. (2018) identificou diferenças nas percepções dos discentes de Ciências Contábeis da instituição pública pesquisada em relação às privadas.

Pesquisas futuras poderiam aplicar os grupos focais em contextos diferentes, comparando, por exemplo, cursos de exatas e humanas, ou o mesmo curso em várias universidades distintas, tanto públicas como privadas. Dessa forma, mesmo com pesquisas qualitativas, poderia ser possível perceber se há uma tendência de generalização em relação às principais características de um professor exemplar para estudantes de graduação em geral.

\section{REFERÊNCIAS}

ALVES, A. C.; TEIXEIRA, V. V. N.; OLIVEIRA, I. G. V. Percepção dos Discentes do Curso de Graduação em Administração em Relação às Disciplinas da Área de Contabilidade. Revista Administração em Diálogo-RAD, v. 19, n. 3, p. 24-48, 2017. DOI:

https://doi.org/10.23925/2178-0080.2017v19i3.32551

AMARAL, L. B.; DE RESENDE FREITAS, A. G.; PINHEIRO, L. E. T. Perfil que define um Professor Exemplar: Percepção dos Alunos da Pós-Graduação Stricto Sensu em Ciências Contábeis do Brasil. XII Encontro Anpcont 09 a 12/06 de 2018 João Pessoa - PB

ANTONELLI, Ricardo Adriano et al. Ao Mestre com Carinho: o Bom Professor Sob a Ótica dos Discentes de Ciências Contábeis da Geração Y. Revista de Educação e Pesquisa em Contabilidade (REPeC), v. 12, n. 1, 2018. DOI: https://doi.org/10.17524/repec.v12i1.1415

BENI, Priscila Ferreira et al. Processo de ensino-aprendizagem e a interação de professores e alunos em um curso de graduação em Administração de Empresas. Administração: Ensino e Pesquisa, v. 18, n. 2, p. 345-374, 2017. DOI: https://doi.org/10.13058/raep.2017.v18n2.565

BUSLER, Jessica; KIRK, Claire; KEELEY, Jared. What constitutes poor teaching? A preliminary inquiry into the misbehaviors of not-so-good instructors. Teaching of Psychology, v. 44, n. 4, p. 330-334, 2017. DOI: https://doi.org/10.1177/0098628317727907

HENKLAIN, Marcelo H. O. et al. Brazilian Faculty and Student Perspectives on Excellent Teaching. New Directions for Teaching and Learning, v. 2018, n. 156, p. 31-39, 2018. DOI: https://doi.org/10.1002/t1.20314 
KINALSKI, D. D. F. et al. Grupo focal na pesquisa qualitativa: relato de experiência. Revista brasileira de Enfermagem, v. 70, n. 2, p. 443-448, 2017. DOI: http://dx.doi.org/10.1590/00347167-2016-0091

KVITKO, L.; LENGLER, F. R. Uma visão do processo de ensino-aprendizagem: estudo de caso com estudantes do curso de graduação em Administração. Gestão Universitária, v. 10 n. 6, p. 1, 2015.

LOWMAN, J. Dominando as técnicas de ensino. São Paulo: Atlas. 2004.

LUMPKIN, A.; MULTON, K. D. Perceptions of teaching effectiveness. The Educational Forum. Taylor \& Francis, p.288-299, 2013.

DOI: https://doi.org/10.1080/00131725.2013.792907

NOGUEIRA, D. R.; FADEL, M. O.; TAKAMATSU, R. T. Em busca da essência de um bom professor: Uma análise sobre a percepção discente nos cursos dos cursos de pós-graduação na área de negócios. Registro Contábil, v. 3, n. 3, p. 12-31, 2012.

SCHMIDT, Paulo et al. Perfil dos alunos do curso de Ciências Contábeis de instituições de ensino do sul do Brasil. ConTexto, v. 12, n. 21, p. 87-104, 2012.

TANAKA, O.; MELO, C. Reflexões sobre a avaliação em serviços de saúde e a adoção das abordagens qualitativa e quantitativa. In: BOSI, M. L. M.; MERCADO, F. J. (Org.). Pesquisa qualitativa de serviços de saúde. Petrópolis: Vozes, 2004. p. 121-136.

TESTA, M. G.; FRONZA, P.; FREITAS, H. Diferenças individuais nas preferências por contato social do estudante e a sua influência na efetividade dos cursos de graduação em administração. IN: $39^{a}$ Assemblea Anual del Consejo Latinoamericano de Escuelas de Administración (CLADEA). Anais... Santiago do Chile, 2005.

TESTA, M. G.; ROHDE, L. R.; LUCIANO, E. M. As preferências de estudantes universitários por contato social. Administração: Ensino e Pesquisa, v. 12, n. 1, p. 93-118, 2011. DOI: https://doi.org/10.13058/raep.2011.v12n1.174 